
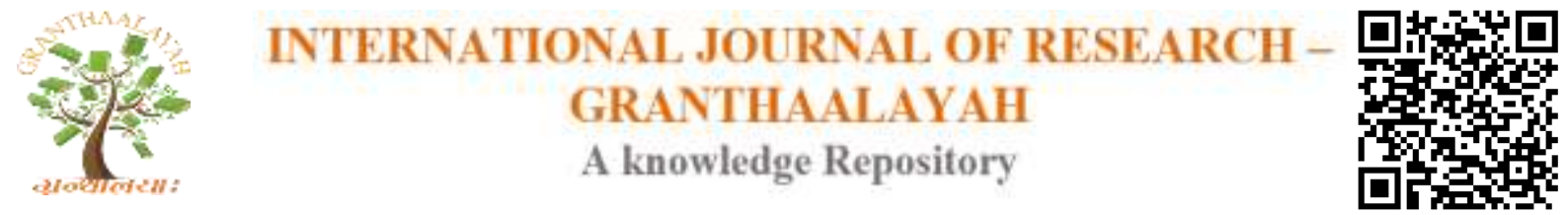

Science

\title{
FUZZY RULE-BASED MODEL FOR OPTIMAL MANAGEMENT OF MARINE PROTECTED AREAS: A CASE STUDY ON THE MARINE RESERVE CERBÈRE-BANYULS
}

\author{
Afraa Ghanem *1, Ali Zaher ${ }^{2}$ \\ ${ }^{* 1}$ Image Laboratory- CNRS, University of Perpignan, France \\ 2 PROMES-CNRS Laboratory, University of Perpignan, France
}

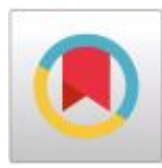

\begin{abstract}
Marine spatial planning (MSP) is considered as one of the most appropriate ways to create and manage marine protected areas (MPAs) around the world. However, conservation constraints and the increase in competition for limited space and resources can generate land use conflicts. The purpose of this study is to develop an approach based on fuzzy inference systems FIS in order to solve the problem of land use conflicts in the Marine Reserve Cerbère-Banyuls in France. The advantage of the proposed method is that expert scientific knowledge in coastal aquaculture activities and the GIS data can be incorporated into a geospatial model to create optimal maps for spatial distribution of activities in the MPAs. This method is applied to the reserve Cerbère-Banyuls and it demonstrated a good efficiency.
\end{abstract}

Keywords: Spatial Planning; Marine Protected Areas; Fuzzy Logic; Land Use; Conflict.

Cite This Article: Afraa Ghanem, and Ali Zaher. (2017). "FUZZY RULE-BASED MODEL FOR OPTIMAL MANAGEMENT OF MARINE PROTECTED AREAS: A CASE STUDY ON THE MARINE RESERVE CERBÈRE-BANYULS." International Journal of Research Granthaalayah, 5(7), 239-251. https://doi.org/10.29121/granthaalayah.v5.i7.2017.2130.

\section{Introduction}

Coastal environments occupy one of the most dynamic interfaces between land and sea, and they support some of the most diverse and productive habitats. Furthermore, marine and coastal areas worldwide are now facing increasing and significant threats, from overfishing, unsustainable humane practices, pollution, costal habitat loss and degradation, and climate change. Therefore, a variety of policies from global to local level have arisen for managing human activities in the marine environment in order to promote the conservation of marine biodiversity. In this context, Marine Protected Areas (MPAs) are created to mitigate human activities impacts and to protect biodiversity and ecosystems by reducing species mortality and habitat deterioration [1], enhancing resilience and resistance of protected communities [2], and developing sustainable human practices inside and outside their boundaries [3]. 
There are many types of MPA, with management arrangements ranging from multiple-use to strict protection within NTZs (No-Take Zones), where all extractive activities are prohibited.

In our work, we consider MPA as multiple-use marine areas where provisions are made for both extractive and non- extractive activities. In these coastal areas, a considerable amount of activities is allowed by a diverse range of users who impact not only on the environment but also on each other such as: commercial and recreational fishing, diving, Kayak and other tourism activities.

Indeed, spatial planning is required and seen as a way of improving decision-making to provide a more transparent process of conflict resolution where there are many demands for the use of marine resources and sea space. In this way, marine protected areas are divided into zones delineated for specific uses considering the biodiversity conservation and accommodating multiple uses of the resource base [4].

Engaging stakeholders in spatial planning process is one of the key factors that contribute to decrease conflict aspects and to increase the socio-economic outcomes of the MPA. In the literature, several decision-making methods and tools have emerged to realize spatial planning for MPAs considering stakeholder preferences. The most popular of these tools is MARXAN (Marine Spatially Explicit Annealing). It is a software that employs stochastic optimization algorithms that provide optimal solutions of spatial panning problems in nature reserves with specified conservation targets [5]. Other methods such as GIS (Geographic Information System) based multi-criteria analysis techniques have been used to address the conflicts among different stakeholders with competing interests in the process of land use allocation through an iterative modification process [6]. Furthermore, a statistical based approach is used by [7] to incorporate the human dimension to evaluate the effectiveness of an MPA.

However, the mentioned methods require quantitative and/or qualitative data which can be collected by a long and complex process that needs expensive monitoring materials and the cooperation of a great number of observers. Therefore, new approaches should be developed to integrate managers knowledge and stakeholders' preferences, to deal with approximations and imprecision in human judgement, and especially to use simple and less expensive data collection way. In this context, fuzzy Inference systems FIS present a viable alternative and may be more suitable. They deal with human reasoning that is approximate rather than precise and they also accommodate imprecision in data throughout the use of linguistic terms [8].

FIS have a multidisciplinary nature and they have been successfully applied in several instances to study the marine environment, such as for: spatial modeling of environmental vulnerability of marine finfish aquaculture [9], for determining the compensatory management actions to anticipate future climate changes in natural protected areas [10], and identifying marine areas for protection from fishing [11]

The aim of this work is to propose an alternative approach, consisting of a fuzzy expert system that combines heterogeneous qualitative and quantitative data in order to obtain optimal solutions for the problems of conflicts between the different activities in the marine reserve CerbèreBanyuls with respect to socio-economic and ecological constraints. 
So, this paper is organized as follows: in the first section "Materials and methods", we describe the study area, the conflict between different activates, the collected data and the proposed methodology. The next part demonstrates the obtained results. And finally, we conclude this paper by pointing out some interesting conclusions and further work directions.

\section{Study Area}

The Natural Marine Reserve of Cerbère-Banyuls is one of the oldest marine protected areas of France situated on the north-western Mediterranean Sea, near the Spanish boundary. It is founded in 1974 to face serious threats from overexploitation, pollution, sedimentation, ocean acidification, and habitat destruction.

The protected zone covers 650 hectares of sea and stretches 6 kilometers from shore until mile and a half offshore. The nature reserve is divided into two management categories with different levels of protection: $10 \%$ of its area is a no-take zone or also called integral reserve and $90 \%$ is a sustainable use zone or known as partial reserve.

The no-take-zone is located in the southern part of the reserve at Cape Rédéris (created in 1979), where the protection is reinforced and all extractive activities are prohibited, except those related to scientific purposes or approved by the advisory committee of the reserve. In the multi-use zone, extractive and non-extractive human activities are permitted and regulated such as commercial fishing, recreational fishing, diving and other tourism activities.

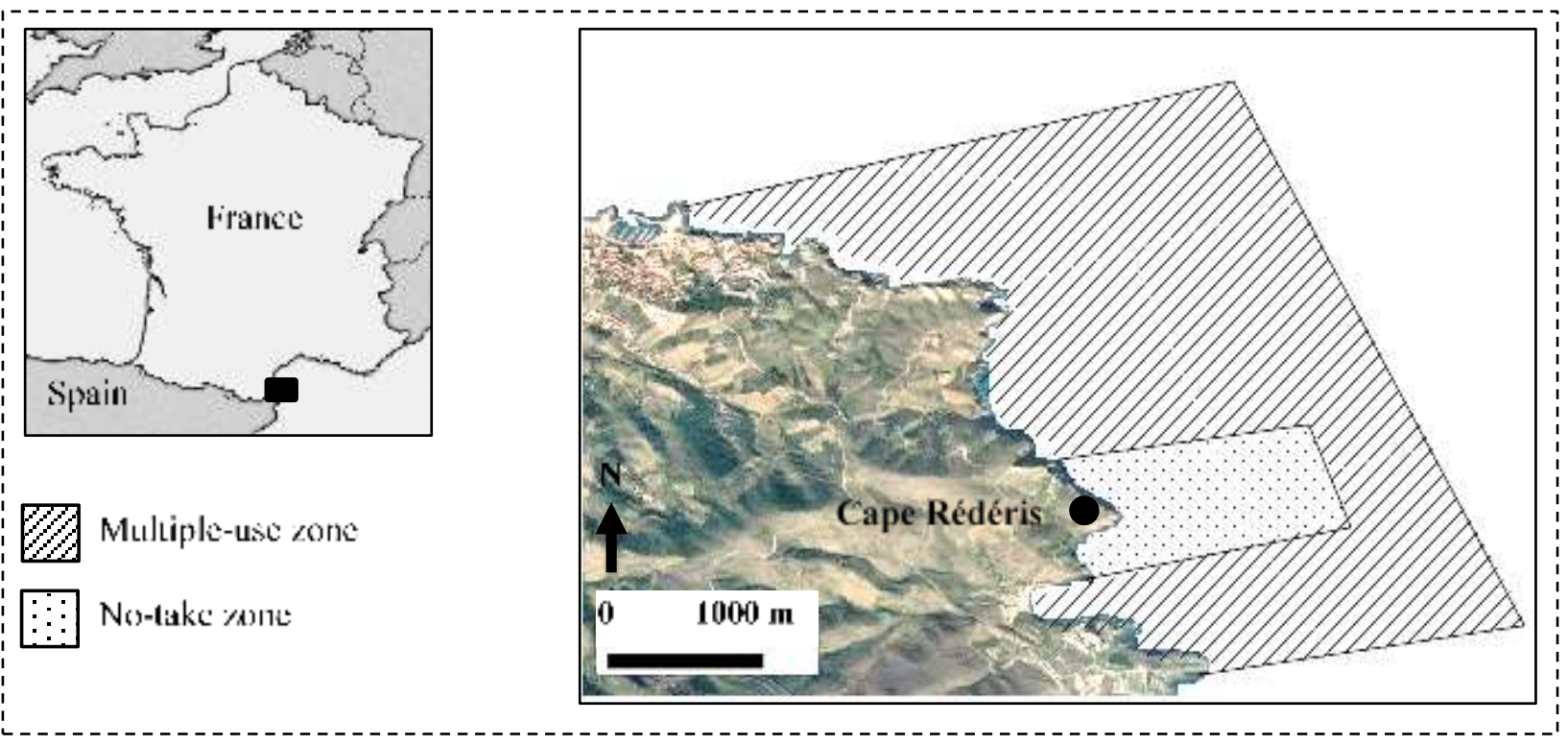

Figure 1: Natural Marine Reserve of Cerbère-Banyuls

\section{Conflicts}

In fact, Cerbère is a commune that relies on marine tourism through which the nature reserve is an important attraction factor and it has generated employment and income. thus, authorities and managers of the nature reserve have a special role to ensure that marine tourism is developed in harmony with environmental considerations. 
Fig. 2 demonstrates the evolution of diverse activities within the multiple-use area over eight years. These activities are classified into four main types as follows:

- Diving: this activity involves scuba diving and snorkeling which continue to be the most popular water-based experiences in the natural reserve. Concurrently, the number of divers is more than 5 million per year.

- Fishing: like commercial fishing, and recreational fishing. These two activities are regulated by quotas, and laws to control the catching of fishes. The reserve regulations allow recreational fishing (free license with an angling effort restricted to 6 shore hooks and 12 hooks per fishing vessel), limit commercial fishing to 8 licenses per year, and prohibit spear fishing, night fishing and bottom trawling.

- Motorized water-based sports: motorized watersports such as jet skiing, wakeboarding, personal hydrofoils, and parasailing, have seen participation numbers rise continuously despite the strict management controls in the reserve.

- Non-motorized water-based sports: Surfing and windsurfing continue to attract large numbers of participants, the same is true, to a lesser degree, for the associated sports of parasurfing and kite surfing. Additionally, kayaking has grown in popularity as an independent as well as a tourism industry component of water-based experiences.

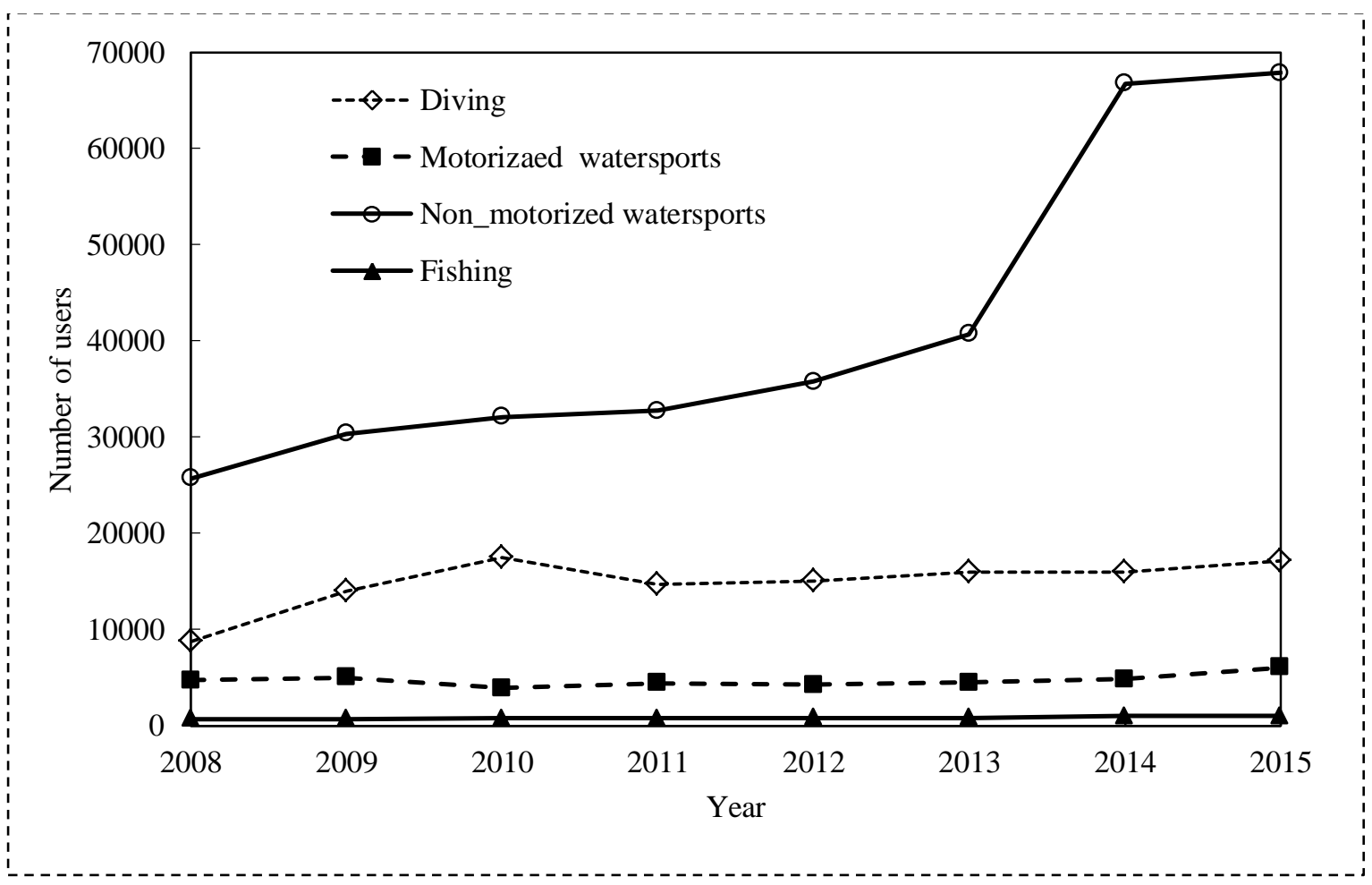

Figure 2: Evolution of maritime activities within the natural reserve of Cerbère-Banyuls.

Like many multiple-use marine protected areas around the world, the nature reserve faces potential conflicts caused by the increasing number of sea space users. Two types of conflict can be observed in the reserve: conflict between nature protection and other users, and conflict between users. 
Concerning the first type of conflict, commercial fishing and recreational activities (angling, boating, whale-watching, scuba-diving, cruise travelling, etc.) have a negative impact on the marine environment caused by, for example: disturbances due to boat bottom color, noise, anchorage, garbage and other waste, releases of hydrocarbons, and other substances. In Table 1, each activity is associated with a number referring to the degree of risk (conflict level between nature protection and human activity) caused by the activity on the ecosystem.

Table 1: Levels of conflicts between nature protection and maritime activities in the PMA. 1:

Low; 2: High; 3: Very High.

\section{Conflict level}

$\begin{array}{llll}\text { Diving (D) } & \frac{\text { Fishing (F) }}{3} & \frac{\text { Motorized watersports (MWS) }}{2} & \frac{\text { Non-motorized }}{\text { watersports(NMWS) }}\end{array}$

Conflicts between commercial recreational users can occur when the needs of one group are compromised by the activities of another. This usually involves competition for access to the same resource, either in space or in time. Conflicts can also occur when one group negatively affects the quality of the experience, or compromises the safety of another.

Examples of common conflicts that can occur between coastal recreational users are:

- Motorized boats can damage the nets of fishers.

- Surfboards and sailboards travelling at speed and compromising divers and swimmers' safety.

- Motorized and non-motorized watersports, like Jet skis and kayaking, create a safety issue for divers and swimmers. In addition, such activities reduce the quality of the experience for other users due to their loud noise.

Resolving such conflicts will inevitably require an effective spatial management involving stakeholders and affected users groups. Solutions often include the need to physically separate activities through the designation of zones, or areas of acceptable activity. The conflicts between users are presented in Table 2.

Table 2: Levels of conflicts between users in the PMA. 0: neutral, no antagonism; 1: slightly negative; 2 : negative; 3 : strongly negative.

$\begin{array}{lllll} & \underline{\mathbf{D}} & \underline{\mathbf{F}} & \underline{\mathbf{M W S}} & \underline{\text { NMWS }} \\ \text { Diving (D) } & 0 & 2 & \frac{3}{3} & 1 \\ \text { Fishing (F) } & 2 & 0 & 2 & 1 \\ \text { Motorized watersports (MWS) } & 3 & 2 & 0 & 3 \\ \text { Non-motorized watersports(NMWS) } & 1 & 1 & 3 & 0\end{array}$

\section{Data Collection}

The first stage involved selecting input variables or indicators that can be used to determine the suitable site for each activity considering stakeholder's preferences and conservation constraints. 
The collected data are composed of quantitative and qualitative data. Concerning quantitative data, they include the bathymetry and the sea-floor structure (or bottom type: sand, rocks, or Posidonia) acquired using multibeam sonar data that provide descriptions of the seafloor's spatial distribution of relief, terrain derivatives, and estimates of bottom composition. These seafloor properties are considered important physical variables governing the distribution of human activities through the marine protected area. Other quantitative data, such as the number of visitors, the spatial and temporal distribution of users and the economic income of each activity, are collected by monitoring process accomplished by mangers and researchers in the reserve from 2008 to 2015 .

The qualitative data are collected by interviews conducted with stakeholders to gain a wide geographical representation of spatial use patterns, ecological and economic impacts of each activity. Specific questions were asked to users about what factors are important when they choose a location for their activity in the reserve, and their preferences for the location attributes such as deep or shallow sites; crowded or uncrowded; near or far. Other questions are posed to mangers, scientist and visitors about the potential conflicts between activities and between nature protection and users in order to determine the degree of conflict and its location.

\section{Fuzzy Rule-Based Model}

Our intelligent spatial planning approach is composed of two stages as presented in (Fig. 3). At the first stage, we use the geophysical characteristics (depth, bottom and distance from the coast) of the studied zone as inputs to a fuzzy rules base. Then, for each activity, we use user's preferences by the fuzzy rules base to obtain a suitability index (SI) that represents the degree of suitability of a given place for the studied activity. The result of this stage is a spatial distribution of the suitability index for each activity. In other words, the potential activities that may be practiced at each location (Latitude, longitude) of the marine protected area can be obtained by the application of the first stage.In the second part and for each zone of marine protected area, the suitability index in addition to the economic and the environmental impacts for each activity are used, to determine the dominant activity in the zone.

Fuzzy logic plays a key role in situations where qualitative data and human expertise are introduced into the modeling, such as in our case, where ecological and socio-economic variables, as well as human perceptions and values are used. For making up a fuzzy inference system FIS, three processes are needed: the fuzzification, the fuzzy rules base and the defuzzification [12]. 


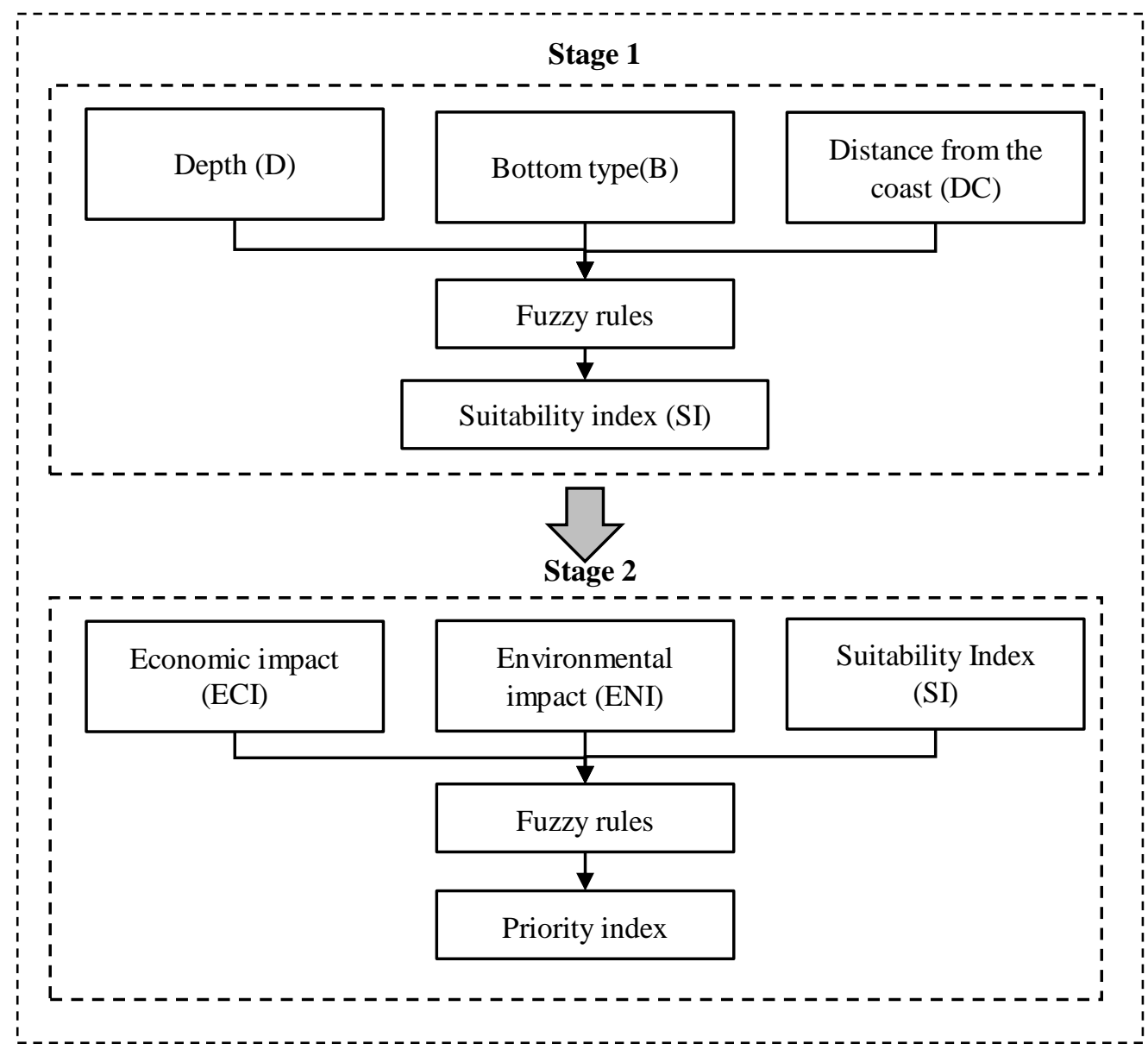

Figure 3: Schematic diagram of the fuzzy rule based model for optimal spatial planning for marine protected areas.

\subsection{Fuzzification}

Fuzzification is the process of transforming all variables (inputs and outputs) in crisp form into linguistic variables. This transformation is done by dividing the given variable into ranges of variation and then assigning each range to an appropriate linguistic category for example: "Low", "High", "Small", etc. These categories represent fuzzy subsets characterized by fuzzy membership functions that give a degree of membership between 0 and 1 for each crisp value of the variable. There are diverse forms of membership functions, the most common of them are triangular, trapezoidal, Gaussian, or singleton. The type of a membership function can be chosen depending on the user experience. For simplicity, we have used triangular and trapezoid shaped membership functions as presented in (Fig. 4 and Fig. 5).

Linguistic categories for variables are discerned directly from user's perceptions of their marine environment. 

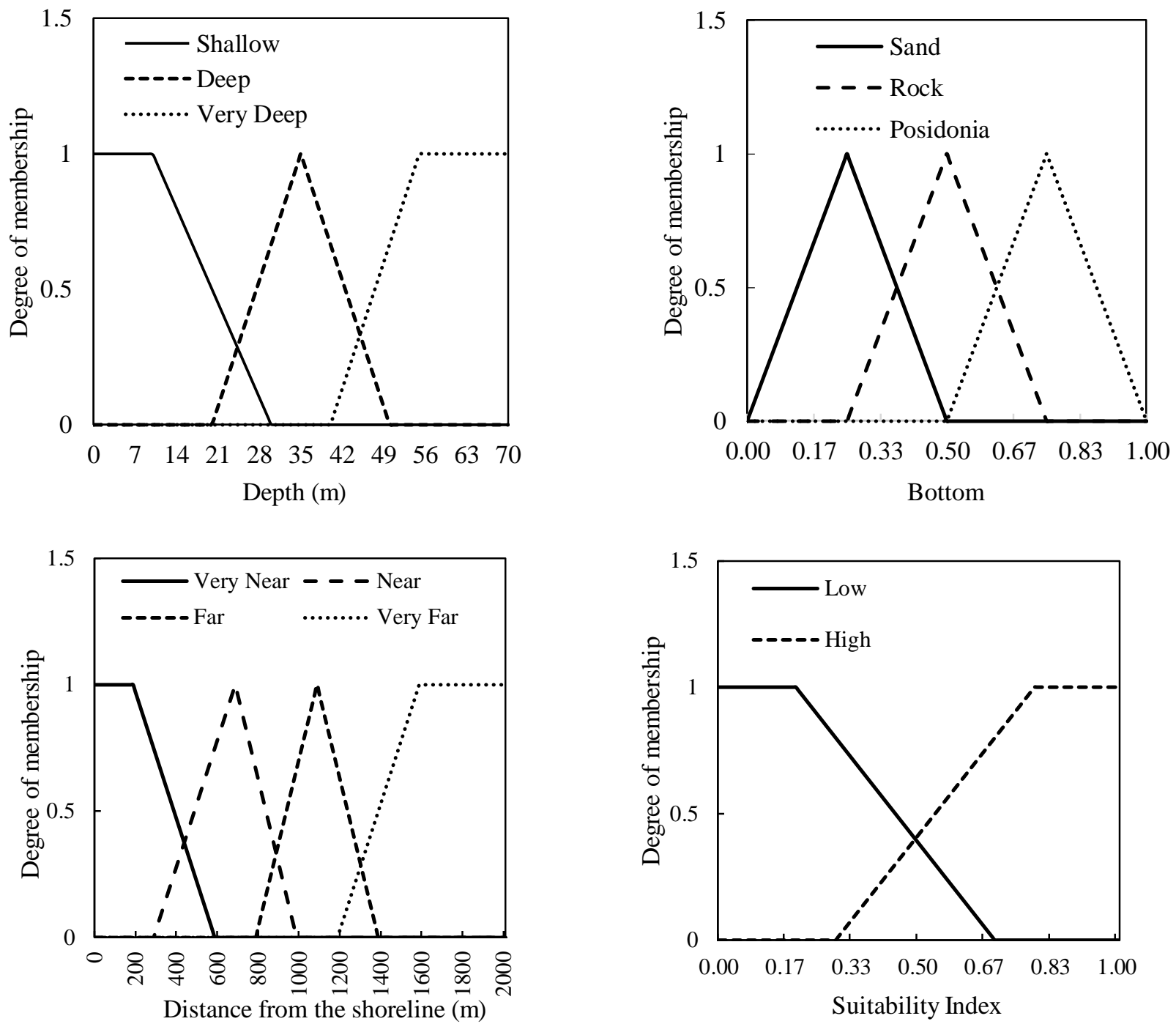

Figure 4: Fuzzification of input and output variables for the first stage.

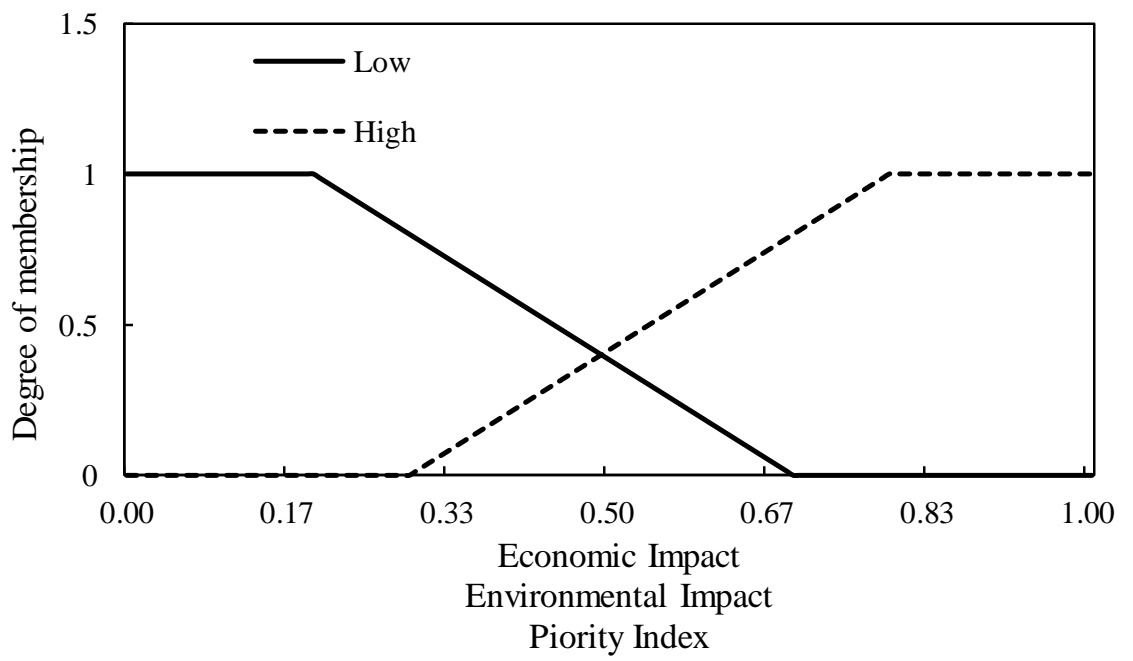

Figure 5: Fuzzification of input and output variables for the second stage. 


\subsection{Fuzzy rules base}

Fuzzy logic rules base is the kernel of a fuzzy inference system, where expert knowledge and user's preferences about the underlying physical system is incorporated. These rules control the process of solving the studied problem using linguistic terms. They are conditional if-then statements that relate a given condition to an outcome. These conditional statements can be can formulated as:

\section{If $A$ is "Low" and B is "High" Then C is "Low"}

Where:

- A and B are inputs.

- $\mathrm{C}$ is the output

- "Low" and "High" are labels of fuzzy sets characterized by appropriate membership functions.

The output of each rule is a fuzzy subset, thus, the fuzzy outputs for all rules must be aggregated in order to obtain one fuzzy set.

At the first stage of our approach, a rules base combining user' preferences and managers expertise is designed for each activity. For example, most fishers preferred to fish, where there are natural habitats or rocks that attract more fish, regardless the deep and the distance from the coast. But some of fishers choose fishing in deep water where there are big fish and others preferred fishing close to the shore. Therefore, we introduced their opinion in some rules formulated as follows:

- R1: If D is "Deep" and B is "Habitats" and DC is "Near" Then SI is "High"

- R2: If D is "Deep" and B is "Habitats" and DC is "Far" Then SI is "Low"

- R3: If D is "Shallow" and B is "Sand" and DC is "Near" Then SI is "Low"

- R4: If D is "Shallow" and B is "Rock" and DC is "Near" Then SI is "High"

- R5: If D is "Very Deep" and B is "Habitats" and DC is "Far" Then SI is "Low"

Concerning divers, most of them choose the seafloor where the rocks form a home for diverse marine spices. In other hand, their preferences for the depth vary according to their experience and the type of diving. For beginner divers and snorkers, they are advised to stay in shallow water but more depth is required for deep dive. We present as example the following rules that control the distribution of diving:

- R1: If D is "Deep" and B is "Rock" Then SI is "High"

- R2: If D is "Shallow" and B is "Rock" Then SI is "high"

- R3: If D is "Shallow" and B is "Sand" Then SI is "Low"

- R4: If D is "Very deep" and B is "Rock" Then SI is "Low"

The same reasoning is used to construct the rules bases that govern the spatial distribution of motorized and non-motorized sports.

As mentioned previously the results of the first stage are a spatial distribution of activities with zones of conflicts due to the interactions between users' preferences. In the second part of our 
approach, we have constructed fuzzy rules bases to assign a priority index to each activity. The dominant activity in a zone of conflict is that has the biggest value of priority. Such fuzzy rules have the form:

- R1: If EC is "High" and ENI is "Low" Then PI is "High"

- R2: If EC is "High" and ENI is "High" Then PI is "Low"

- R3: If EC is "Low" and ENI is "Low" Then PI is "Low"

\subsection{Defuzzification}

When fuzzy rules are applied to the fuzzified inputs, the output of each rule is still in fuzzy format such as "Low" or "High". For each rules base, the outputs of all rules are aggregated to form one fuzzy subset. Then, it is necessary to translate 'low' or "High" from their prevailing fuzzy state to a quantitative suitability or priority score. Many ways can be used to achieve this task. The most commonly used technique is that developed by Sugno in 1985 and called center of area or center of gravity [13]. Due to its high performance demonstrated in different applications, this technique is adopted in our work. The center of gravity can be expressed by the following equation [14]:

$Z_{C O G}=\frac{\int_{z} \mu_{A}(z) \cdot z \cdot d z}{\int_{z} \mu_{A}(z) \cdot d z}$

Where: $Z_{C O G}$ is the crisp output, $\mu_{A}(z)$ is the aggregated membership function and $z$ is the output variable.

\section{Results and Discussions}

We have applied the fuzzy rules based model to obtain spatial distribution of human activities depending on users 'preferences and expert knowledge. The method is divided into two parts, the objective of the first part is to find the suitable zone for each activity by estimating a suitability index SI. The results of this part are presented in (Fig. 6).

Concerning Scuba-diving, the dominant factors affecting the values of the suitability index are the depth and the sea floor structure. So, this index takes big values where the water is shallower than $20 \mathrm{~m}$ and where there are rocks, coral and/or natural habitats. On the other hand, the two parameters playing a role in the distribution of fishing are the distance from the cost and the sea floor structure. Thus, fishing occurs greatly in nearshore zones where rocks and coral form a home for many marine spices. Considering motorized and non-motorized sports, they are distributed similarly according to the distance from the shoreline.

The results demonstrate conflicts areas between the different users in the natural reserve (Fig. 7.a) due the interactions between their preferences. In order to solve these conflicts, the resulted suitability indices, environmental and economic impacts for each activity are used as inputs to the second stage of the fuzzy model. The results are presented in (Fig. 7.b) where each activity is 
assigned to a special zone with respect to users' preferences and management constraints to maintain sustainable development in the reserve.

Regarding the environmental impact, fishing that has a high negative impact on biodiversity is very far from the no-take zone. By following the same logic, motorized sports are interdict in the no-take zone because of their noise pollution.

The area of the zone assigned to each activity is obtained by taking into account the economic income for each activity. Therefore, about $7 \%$ of the reserve area is attributed to fishing which has the minimum economic importance but more than $12 \%$ and $22 \%$ are attributed respectively to diving and motorized sports that have higher economic incomes.

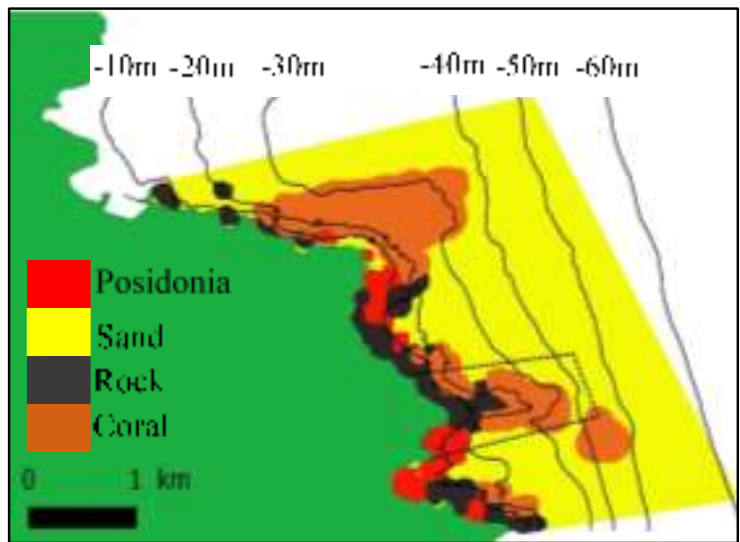

(ii)

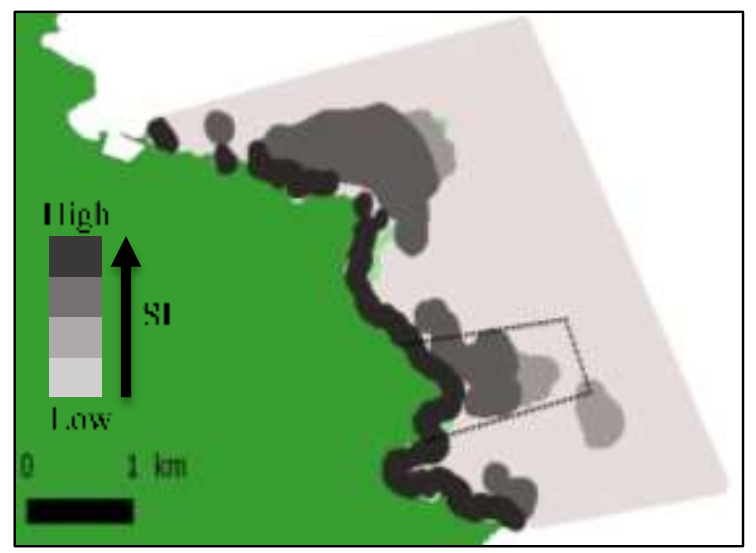

(c)

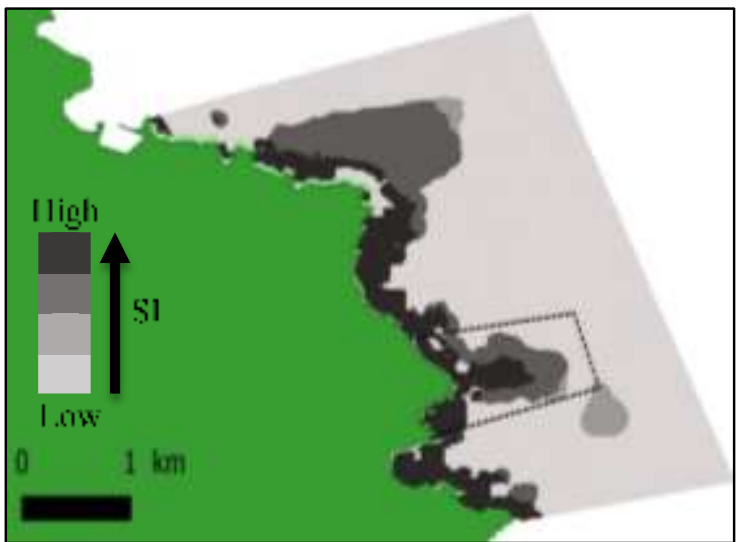

(b)

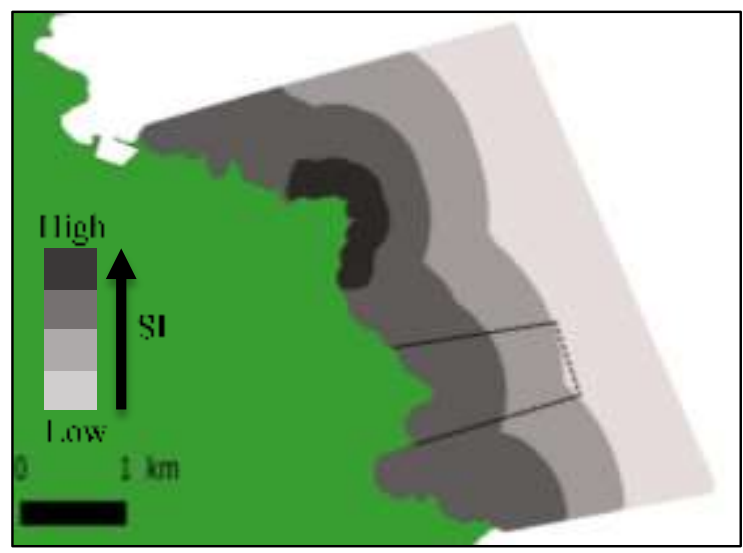

(d)

Figure 6: Inputs and results of the first part of the model: (a) bathymetry and sea-floor data used as inputs, (b) SI for diving, (c) SI for fishing and (d) SI for motorized and Non-motorized sports 


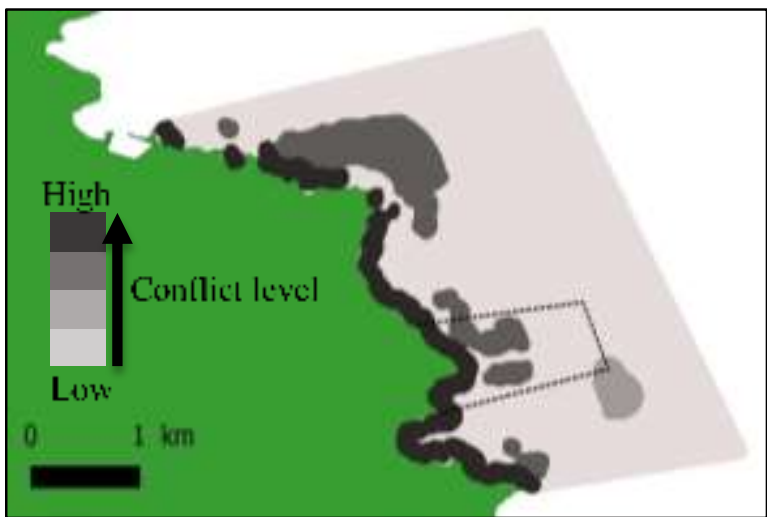

(ii)

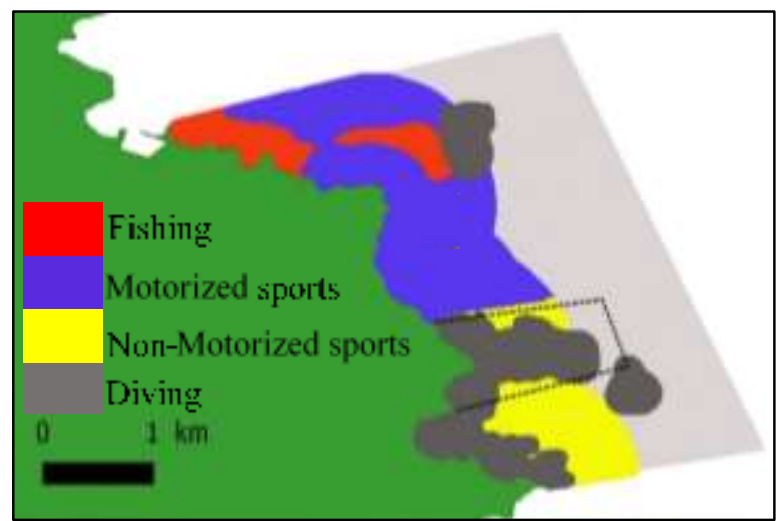

(b)

Figure 7: Conflict zones and spatial distribution of activities: (a) spatial distribution of conflict levels and (b) spatial distribution of activities obtained from the second stage of the fuzzy model.

\section{Conclusions \& Recommendations}

The current paper aims to demonstrate the potential use of fuzzy logic for mapping and solving conflicts between users in marine protected areas as part of the marine spatial planning MSP program in the European Union to support sustainable growth in the marine and maritime sectors. The absence of an efficient marine spatial planning approach implies the presence of many negative impacts on the environment, society and economy. Our proposed fuzzy rules based model provides a performant mechanism to combine qualitative and quantitative data in assessing each zone of a given marine protected area to a special activity.

This model allowed us to overcome the problem of other approaches dealing with quantitative data that require complex tools and great investments. Quantitate variables such as the depth, the seafloor structure and the distance from the shoreline are used as inputs to the first part of our model to determine the suitable for each activity. Qualitative variables like environmental and economic impacts are used in the second part of our approach to solve the conflict between users. The fuzzy rules are built depending on users' preferences and managers knowledge. The obtained results form a successful spatial management plan for the reserve marine CerbèreBanyuls.

\section{References}

[1] Sarah Lester, Benjamin Halpern, Kirsten Grorud-Colvert, Jane Lubchenco, Benjamin Ruttenberg, Steven Gaines, Satie Airamé, and Robert Warner. (2009). "BIOLOGICAL EFFECTS WITHIN NO-TAKE MARINE RESERVES: A GLOBAL SYNTHESIS.” Marine Ecology Progress Series, 384, 33-46. https://doi.org/10.3354/meps08029.

[2] F Simonetta Fraschetti, Giuseppe Guarnieri, Stanislao Bevilacqua, Antonio Terlizzi, and Ferdinando Boero. (2013). "PROTECTION ENHANCES COMMUNITY AND HABITAT STABILITY: EVIDENCE FROM A MEDITERRANEAN MARINE PROTECTED AREA." PLoS One, 8(12), e81838. https://doi.org/10.1371/journal.pone.0081838.

[3] Mireille Harmelin-Vivien, Laurence Le Diréach, Just Bayle-Sempere, Eric Charbonnel, José Antonio García-Charton, Denis Ody, Angel Pérez-Ruzafa, Olga Reñones, Pablo Sánchez-Jerez, and Carlos Valle, (2008). "GRADIENTS OF ABUNDANCE AND BIOMASS ACROSS 
RESERVE BOUNDARIES IN SIX MEDITERRANEAN MARINE PROTECTED AREAS: EVIDENCE OF FISH SPILLOVER?” Biological Conservation, 141(7), 1829-1839.

[4] Marilena Papageorgiou. (2016). "COASTAL AND MARINE TOURISM: A CHALLENGING FACTOR IN MARINE SPATIAL PLANNING.” Ocean \& Coastal Management, 129,44-48. https://doi.org/10.1016/j.ocecoaman.2016.05.006.

[5] Nuno Sales Henriques, Pedro Monteiro, Luis Bentes, Frederico Oliveira, Carlos Afonso, and Jorge Gonçalves. (2017). "Marxan as a zoning tool for development and economic purposed areas-Aquaculture Management Areas (AMAs)." Ocean \& Coastal Management, 141, 90-97. https://doi.org/10.1016/j.ocecoaman.2017.03.016.

[6] I Nyoman Radiarta, Sei-Ichi Saitoh, and Akira Miyazono. (2008). "GIS-BASED MULTICRITERIA EVALUATION MODELS FOR IDENTIFYING SUITABLE SITES FOR JAPANESE SCALLOP (MIZUHOPECTEN YESSOENSIS) AQUACULTURE IN FUNKA BAY, SOUTHWESTERN HOKKAIDO, JAPAN." Aquaculture, 284 (1-4), 127-135. https://doi.org/10.1016/j.aquaculture.2008.07.048.

[7] Jacqueline Alder, Dirk Zeller,Tony Pitcher, and Rashid Sumaila. (2002). "A METHOD FOR EVALUATING MARINE PROTECTED AREA MANAGEMENT." Coastal Management, 30(2),121-13.

[8] Ali Zadeh. (1965). "Fuzzy sets.” Information and Control, 8(3), 338-353.

[9] Juan Moreno Navas, Trevor Telfer, and Lindsay Ross. (2011). "SPATIAL MODELING OF ENVIRONMENTAL VULNERABILITY OF MARINE FINFISH AQUACULTURE USING GIS-BASED NEURO-FUZZY TECHNIQUES.” Marine Pollution Bulletin, 62(8), 1786-1799. https://doi.org/10.1016/j.marpolbul.2011.05.019.

[10] Tony Prato. (2012). "INCREASING RESILIENCE OF NATURAL PROTECTED AREAS TO FUTURE CLIMATE CHANGE: A FUZZY ADAPTIVE MANAGEMENT APPROACH." Ecological Modelling, 242, 46-53. https://doi.org/10.1016/j.ecolmodel.2012.05.014.

[11] Lydia Teh and Louise Teh. (2011). "A FUZZY LOGIC APPROACH TO MARINE SPATIAL MANAGEMENT.” Environmental Management, 47(4), 536-545.

[12] Ebrahim Mamdani, and Sedrak Assilian. (1975). "AN EXPERIMENT IN LINGUISTIC SYNTHESIS WITH A FUZZY LOGIC CONTROLLER.” International Journal of Man-Machine Studies. 7(1), 1-13.

[13] Tomohiro Takagi, and Michio Sugeno. (1985). "FUZZY IDENTIFICATION OF SYSTEMS AND ITS APPLICATIONS TO MODELING AND CONTROL." IEEE Transactions On Systems, Man, And Cybernetics, 15 (1), 116-32.

[14] Ali Zaher, Yao N'goran, Frédérik Thiery, Stéphane Grieu, and Adama Traoré. (2017). "Fuzzy rule-based model for optimum orientation of solar panels using satellite image processing." IOP Conf. Series: Journal of Physics, doi:10.1088/1742-6596/783/1/012058.

*Corresponding author.

E-mail address: afraaghanem80@ gmail.com 